\title{
Interações entre universidade e tecido produtivo: experiências em atividades tradicionais de Santa Catarina
}

Hoyêdo Nunes Lins ${ }^{1}$

\begin{abstract}
Resumo: Este estudo ocupa-se de relações entre universidade e tecido produtivo em atividades tradicionais. O foco é duplo, a maricultura de ostras e mariscos e a produção de artigos de vestuário, na região de Florianópolis (SC). As duas admitem abordagem no marco das relações entre universidade e tecido produtivo, que na maricultura implicam a Universidade Federal de Santa Catarina, a Empresa de Pesquisa e Extensão Rural de Santa Catarina e membros das comunidades litorâneas, e na indústria do vestuário envolvem a criação, entre outras coisas, de um Bacharelado em Moda - Habilitação em Design de Moda na Universidade do Estado de Santa Catarina, depois completado por ensino de pós-graduação. Considerando as especificidades, o estudo compara as duas experiências quanto aos seus movimentos e aos resultados das interações entre universidade e tecido produtivo, e tangência a questão da sua importância para o desenvolvimento local e regional.
\end{abstract}

Palavras-chave: relações entre universidade e atividades produtivas; Florianópolis (SC); maricultura de moluscos; indústria do vestuário.

\section{University-industry interactions: experiences in traditional activities of Santa Catarina}

\begin{abstract}
This article is about the interactions between universities and production in traditional activities. Its focus is twofold: mariculture of mollusks and clothing production in the area of Florianópolis (Santa Catarina State, Brazil). Both analyses can take into account the discussion about university-industry relations. In the former activity, such relations involve the Universidade Federal de Santa Catarina, the Empresa de Pesquisa e Extensão Rural de Santa Catarina and people living in seaboard communities. In the second activity, they concern among other

1 Professor do Departamento de Ciências Econômicas e do Programa de Pós-Graduação em Economia da Universidade Federal de Santa Catarina. E-mail para contato: hnlins@cse.ufsc.br
\end{abstract}


things the creation and operation of a graduate course on Fashion - Qualification in Fashion Design, at the Universidade do Estado de Santa Catarina, that was soon followed by a postgraduate course. Without leaving aside the specific features, the paper compares both experiences in terms of results of the university-industry interactions, and briefly approaches the question of their importance for local and regional development.

Keywords: university-industry relations; Florianópolis (SC); mariculture of mollusks; cloth production.

JEL: O39; L67; Q22

\section{Introdução}

No Brasil, como em nível internacional, o debate sobre as relações entre universidade e tecido produtivo tende a privilegiar setores de maior intensidade tecnológica. A perspectiva adotada nesse debate refere-se basicamente aos sistemas de inovação, focalizados nas escalas nacional ou regional e local, e as abordagens apresentam-se costumeiramente pontuadas spor críticas ao que se entende ser um traço recorrente dessas relações. Trata-se, como detectado em bom número de casos, do caráter inegavelmente rarefeito de tais vínculos, que só em algumas experiências permitem observar interações efetivamente bem sucedidas entre as esferas da ciência e da tecnologia.

O presente estudo objetiva discutir a problemática das ligações entre universidade e tecido produtivo com foco não na alta tecnologia, mas em atividades tradicionais. Dois setores de atividades são contemplados, ambos pertencentes à estrutura socioprodutiva da região de Florianópolis, polarizada por município do mesmo nome, capital do Estado de Santa Catarina.

Um desses setores é a maricultura, ligada ao cultivo de ostras e mariscos envolvendo numerosos habitantes de localidades litorâneas, muitos deles ex-pescadores artesanais afetados pelo declínio da pesca e pelo decorrente estreitamento das possibilidades de reprodução social nas suas comunidades. $\mathrm{O}$ outro setor vincula-se à produção de artigos de vestuário, que mobiliza mulheres de localidades e bairros periféricos na condição de assalariadas em pequenas e médias empresas, e também como trabalhadoras em domicílio e/ou integrantes de empreendimentos coletivos informais (cooperativas de costureiras), em quase todos os casos significando canalização de funções e tarefas terceirizadas por empresas. Ambos são segmentos da estrutura produtiva local que exibem destacada "capilarização social", isto é, incidência por assim dizer pulverizada, em escala de comunidade.

O fundamento da pesquisa é que essas atividades admitem abordagem no marco das relações entre universidade e tecido produtivo. A maricultura evoluiu 
na esteira de importantes interações entre a Universidade Federal de Santa Catarina (UFSC), a Empresa de Pesquisa e Extensão Rural de Santa Catarina (EPAGRI), do governo estadual, e moradores das comunidades litorâneas. A indústria do vestuário foi “organizada” por medidas que, além de entidades de representação, coordenação e defesa dos interesses dos fabricantes, incluíram a criação de um curso hoje denominado Bacharelado em Moda - Habilitação em Design de Moda, na Universidade do Estado de Santa Catarina (UDESC), posteriormente complementado por formação em nível de pós-graduação.

Considerando as especificidades setoriais, o estudo compara as duas experiências quanto aos movimentos e ações protagonizados e particularmente quanto às características e aos resultados dos vínculos entre universidades e atividades produtivas. Por extensão o estudo discute, para um caso e para o outro, o significado dos percursos trilhados em termos de contribuição ao desenvolvimento local.

O texto apresenta-se organizado em quatro seções, além desta introdução e das considerações finais. A seguir discorre-se sobre a problemática das interações entre universidade e tecido produtivo, de modo amplo, visando dar enquadramento à pesquisa específica. As duas seções seguintes abordam, pela ordem, a maricultura e a indústria do vestuário na área de estudo, na perspectiva das relações entre universidade e tecido produtivo. Posteriormente, salientam-se as particularidades entre as duas experiências, discutindo aspectos de caracterização e, sobretudo, de resultados, com ênfase nos reflexos em matéria de desenvolvimento local.

\section{O tema das interações entre universidade e tecido pro- dutivo}

A problemática do relacionamento entre universidade e tecido produtivo adquiriu importância redobrada e alcançou grande visibilidade no bojo dos processos econômicos observados em escala mundial desde as últimas décadas do século XX, pelo menos. A assim chamada globalização da economia, representando oportunidades e principalmente desafios, impôs a aquisição de conhecimento e a capacidade de inovar como requisitos básicos para a inserção positiva de empresas e setores produtivos em ambientes concorrenciais cada vez mais exigentes, além de balizados por fatores que refletem escalas amplas de determinação.

Nesse contexto, as interações entre tecido produtivo e tecido institucional ganharam enorme relevância, passando a figurar quase como um "recurso". O significado de que se revestem esses vínculos, atualmente, é aspecto do que Lundvall e Borrás (1997: 35) designam como economia da aprendizagem, quer dizer, "uma economia em que a habilidade para aprender é crucial para o sucesso econômico de indivíduos, regiões e economias nacionais". 
Tendo em vista a sua natureza como integrante do sistema de produção de conhecimento, a universidade é tipo de instituição capaz de desempenhar papéis estratégicos nesse contexto econômico, embora o debate sobre tal assunto exiba posições diferenciadas, como assinalam Godin e Gingras (2000). Ênfase particular nessa proeminência da universidade é colocada pela perspectiva analítica da Hélice Tripla, que ressalta as relações, envolvendo diferentes arranjos institucionais, entre universidade, indústria e governo. Ostentam maior realce no correspondente debate as estruturas de inter-relações que se caracterizam pela interpenetração dessas três esferas, com a emergência de organizações híbridas, o que Leydesdorff e Etzkowitz (1998) caracterizam como modelo da Hélice Tripla III. No marco da Hélice Tripla III, com efeito, o

objetivo comum é materializar um ambiente inovativo abrangendo firmas na forma de spin-offs de universidades, iniciativas trilaterais para o desenvolvimento econômico baseado no conhecimento e alianças estratégicas entre firmas (grandes e pequenas, operando em áreas diferentes e com diferentes níveis de tecnologia), laboratórios governamentais e grupos de pesquisa acadêmica (Etzkowitz \& Leydesdorff 2000: 112).

No que concerne ao papel específico da universidade, postula-se que essa instituição "pode desempenhar um mais poderoso papel em termos de inovação em sociedades crescentemente baseadas em conhecimento" (Etzkowitz \& Leydesdorff 2000: 109). Esse entendimento deriva, por exemplo, de constatação segundo a qual as "universidades parecem estar passando por uma segunda revolução acadêmica: a função econômica da universidade está cada vez mais institucionalizada, o que se adiciona à diferenciação entre educação superior e pesquisa" (Leydesdorff \& Etzkowitz 1996:283).

É essencial destacar que o relacionamento entre universidade e tecido produtivo, particularmente no formato captado pelo modelo da Hélice Tripla III, tende a reverberar mais intensamente em escalas locais e regionais. Isso é verdade sobretudo quando se verifica "territorialização" da economia (Storper 1997), situação em que os desdobramentos dos arranjos institucionais centrados no conhecimento e na inovação apresentam-se comparativamente mais consequentes. Ao mesmo tempo, o território - o local, a região - representa escala que potencializa o desempenho interinstitucional nos termos aqui focalizados, haja vista a proximidade, nas várias acepções desse termo.

O nível de exigência que isso impõe à universidade, inevitavelmente guindada, segundo essa perspectiva, à condição de agente central para o desenvolvimento de cidades e regiões, é nada menos que desafiador. Com efeito:

A crescente importância do nível subnacional em termos econômicos e políticos oferece um foco territorial ao novo papel da universidade na economia do conhecimento. Há uma ênfase ampliada na sua contribuição para a competitividade mediante a canalização do benefício econômico proporcionado pela ciência e 
tecnologia, para o que a escala subnacional desempenha um importante papel. Entretanto, simultaneamente ao atendimento dessas novas demandas, as universidades [também] devem responder aos desafios, oportunidades e ameaças globais e continuar a preencher suas funções tradicionais de ensino e pesquisa (Harloe \& Perry 2004: 216).

A América Latina não é exceção na tendência mundial de fortalecimento das interações entre universidade e tecido produtivo. Sutz (2000) aponta duas formas básicas desses vínculos no subcontinente. De um lado, relações desenvolvidas a partir da necessidade do setor produtivo por conhecimento disponibilizado no meio acadêmico para solucionar problemas específicos (um enfoque de tipo bottom-up). De outro lado, ligações escoradas no desempenho das instituições, isto é, derivadas da institucionalização de esforços protagonizados na universidade, no setor produtivo e na esfera governamental (com perfil top-down).

Contudo, os resultados dessas inter-relações costumam ser precários, segundo diferentes avaliações. Tal característica encontra explicação, de uma parte, em condições estruturais, como uma inserção na economia mundial historicamente pouco vinculada ao conhecimento e à inovação. De outra parte, têm igualmente peso processos mais ou menos recentes, como os relativos às reformas do Estado, traduzidas, entre outras coisas, em privatizações que, abrangentes, não raro significaram desnacionalização de segmentos do aparato produtivo.

No Brasil, impulso considerável às interações entre universidade e tecido produtivo originou-se da conjuntura de crise vivenciada nos anos 1980. O estrangulamento financeiro do setor público e a redução dos investimentos em ciência e tecnologia, entre outras coisas, provocaram aproximação entre instituições de ensino e pesquisa e o setor industrial (Baldini \& Borgonhoni 2007). A experiência de incubar empresas, como forma institucional desse tipo de vínculo, logrou alcançar disseminação (Vedovello et al. 2001), sendo ilustrativo que numerosos estudos de caso sobre esses vínculos, inclusive evocando questões de desenvolvimento local, digam respeito a essa modalidade (Vedovello 2001; Diniz \& Oliveira 2006).

Nos anos 1990, sob o signo de uma maior exposição da indústria nacional à concorrência estrangeira, por conta da desregulamentação da economia e da abertura comercial, promover a competitividade tornou-se requisito indispensável. Esse entendimento perpassou iniciativas de busca de dinamismo competitivo principalmente vinculado às empresas de base tecnológica. Para tanto, recorrer ao conhecimento produzido na universidade e implementar grandes programas de alcance nacional, articulando instituições governamentais, empresas e universidades, perfilaram-se como tipos de providências frequentemente exploradas. Cabe assinalar que tal quadro não se revelou imune a críticas, ao menos pelo ângulo dos interesses da universidade. "A idéia generalizada de que existiria um ganho para a atividade de pesquisa 
desenvolvida na universidade decorrente de uma maior interação com a empresa privada passou a ser revista" (Dagnino 2003: 301).

De todo modo, segundo assinalam Suzigan e Albuquerque (2007), o "padrão de interação" entre universidade e tecido produtivo revela-se limitado no Brasil, deixando a desejar quanto à capacidade de imprimir dinamismo econômico efetivamente escorado na inovação. Os casos de reconhecido sucesso são específicos, aparecendo como "pontos de interação" entre ciência e tecnologia em cuja base podem ser detectadas raízes históricas e trajetórias de longa duração.

Esse é o marco geral das experiências de "diálogo" entre universidade e tecido produtivo tratadas neste artigo.

\section{Interações entre universidade e tecido produtivo: a maricultura}

O crescimento da maricultura em escala mundial não passou ao largo do Brasil, onde o setor exibe trajetória marcante pelo menos no Estado de Santa Catarina. No litoral desse estado, de quase 600 quilômetros, surgiu e se desenvolveu o cultivo de mexilhões e ostras (Figura 1), seguido por alguns resultados com camarões e outras tentativas. Santa Catarina ganhou grande destaque no universo maricultor brasileiro, particularmente na ostreicultura, pois já em meados da década de 1990, quando a produção era uma simples fração do que se alcançou posteriormente, anunciou-se em todo o país que a "ostra dá lucro no mar catarinense" (Miura 1996: 8).

FIGURA 1. SANTA CATARINA - PRODUÇÃO DE MOLUSCOS CULTIVADOS (1991-2007)

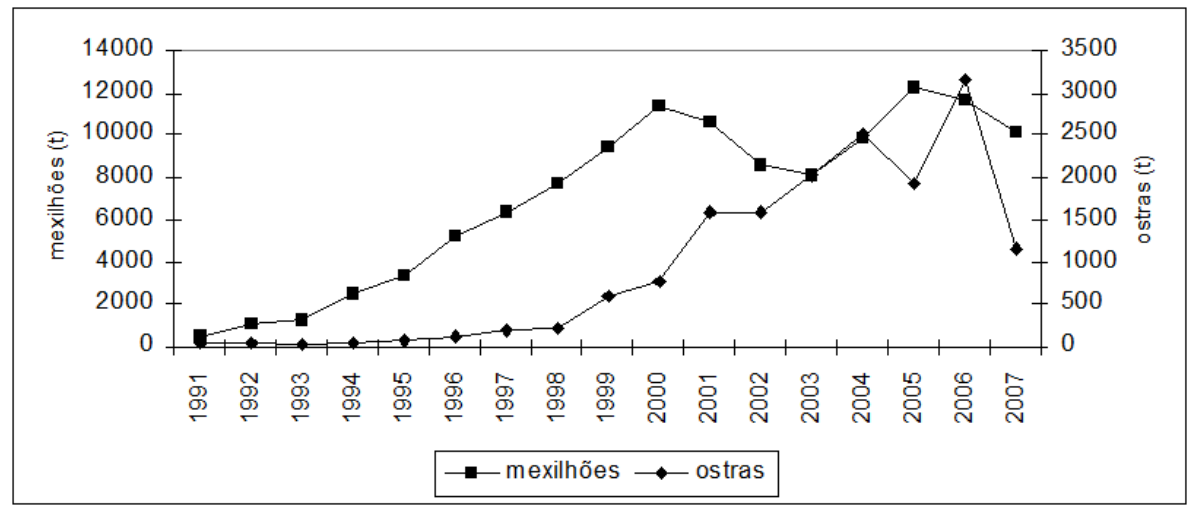

FONTE: Elaboração do autor com dados da EPAGRI (www.epagri.rct-sc.br/) 
O cultivo de moluscos em geral mostra-se pulverizado na metade norte dessa costa. Todavia, o segmento de ostras é fortemente concentrado na região de Florianópolis. Segundo dados da EPAGRI, obtidos em www.epagri.rct-sc.br/, em 2007 o Município de Florianópolis respondeu por 69\% de toda a produção estadual de ostras cultivadas. Somando-se as quantidades de Palhoça e São José, outros municípios dessa região onde também se cultivam ostras, o resultado supera $90 \%$ do total.

Deve-se sublinhar, na perspectiva deste artigo, que essa trajetória da maricultura é indissociável das atividades da Universidade Federal de Santa Catarina (UFSC) e da EPAGRI. Na UFSC, o vínculo remonta ao início da década de 1980, quando o Departamento de Aquicultura criou um Laboratório de Ostras para estudar as possibilidades de cultivo de ostras nativas. Os frustrantes resultados fizeram as atenções se voltarem à ostra japonesa ou do Pacífico, espécie exótica tornada alvo principal daquele laboratório, depois transformado em Laboratório de Cultivo de Moluscos Marinhos (LCMM), atualmente Laboratório de Moluscos Marinhos (LMM) (www.lmm.ufsc.br/). Trata-se de ostra cujas primeiras sementes foram importadas pelo Brasil nos anos 1970 e "que se desenvolve bem em cativeiro - e se adaptou rápido ao clima do litoral catarinense (...)” (Barardi et al. 2001: 70). Também naquele período começaram as pesquisas com mexilhões.

Na EPAGRI, a participação decorreu de interesse no que acenavam as pesquisas da UFSC quanto à criação de alternativas nas comunidades litorâneas. A aproximação aos laboratórios da UFSC desencadeou processo em que técnicos da EPAGRI buscaram formação em maricultura. A partir daí a atividade se disseminou, com esse órgão desempenhando importante papel em mobilização comunitária, informação e assistência técnica por meio de extensionistas. A EPAGRI envolveu-se também em administração, regulamentação e controle, junto com órgãos ligados ao meio ambiente, e na organização dos produtores em associações e cooperativas.

Bastante fértil foi a parceria, de 1993 a 2003, entre o então LCMM e a Canadian International Development Agency (CIDA). Dela resultou o Brazilian Mariculture Linkage Program (BMLP), financiado pela CIDA e concebido para ajudar no combate à pobreza em comunidades pesqueiras no Brasil. Esse programa englobou cinco universidades federais brasileiras, entre elas a UFSC, e três canadenses, com intercâmbios para capacitação de recursos humanos brasileiros no Canadá e a vinda de produtores canadenses ao Brasil.

Como se nota, em Santa Catarina a maricultura baseou-se em teia de relações implicando instituições de ensino e pesquisa, órgãos governamentais e parcerias internacionais. A figura 2 sistematiza esses vínculos, que remetem à problemática das interações entre universidade e tecido produtivo, alcançando também órgãos governamentais, conforme focalizado na segunda seção. $\mathrm{O}$ resultado desse arranjo foi uma irrefutável inovação no litoral catarinense - um novo setor de atividades foi entronizado -, escorada por ligações interinstitucionais em si mesmas revestidas do sentido de inovação. 
O papel da UFSC mostrou-se decisivo nesse percurso, pois foi no âmbito de suas estruturas laboratoriais que ocorreram as pesquisas sobre tecnologias de cultivo. O problema da obtenção de sementes de moluscos mereceu especial atenção. No segmento de ostras, por se tratar de espécie não nativa, uma etapa chave implicou produção em laboratório. Desse modo, o então LCMM privilegiou estudos sobre produção de larvas e sementes de ostras do Pacífico, tanto que esse laboratório se transformou no principal fornecedor aos ostreicultores. No segmento de mexilhões, as sementes podem ser obtidas por raspagem nos costões (bancos naturais) ou pela utilização de coletores artificiais (em que as larvas fixam-se naturalmente). É a segunda forma a compatível com uma maricultura sustentável, e seu aprimoramento foi priorizado nas pesquisas.

Merece destaque que o processo de ampliação do conhecimento e desenvolvimento tecnológico tenha sido marcado pelas interações entre produtores e pesquisadores. "Não houve [na maricultura catarinense] um pacote tecnológico pronto, mas sim a (...) adaptação da tecnologia conhecida em [outros] países (...). Geralmente as grandes linhas de ação são discutidas entre pesquisadores, extensionistas e produtores" (Rosa 1997: 116). No cultivo de ostras, cabe mencionar relações com produtores de Santo Antônio de Lisboa, na costa noroeste da Ilha de Santa Catarina. No de mexilhões, deve-se referir à comunidade de Enseada do Brito, no trecho continental sul da região da Grande Florianópolis. Tais vínculos - evidenciando a importância da extensão universitária pari passu com a pesquisa - mostraram-se fundamentais, pois nutriram a investigação científica, contribuíram para o aperfeiçoamento das práticas de cultivo e, na esteira dos resultados, serviram para atrair o interesse de outras pessoas nas comunidades.

FIGURA 2. INTERAÇÕES BÁSICAS NA MARICULTURA EM SANTA CATARINA

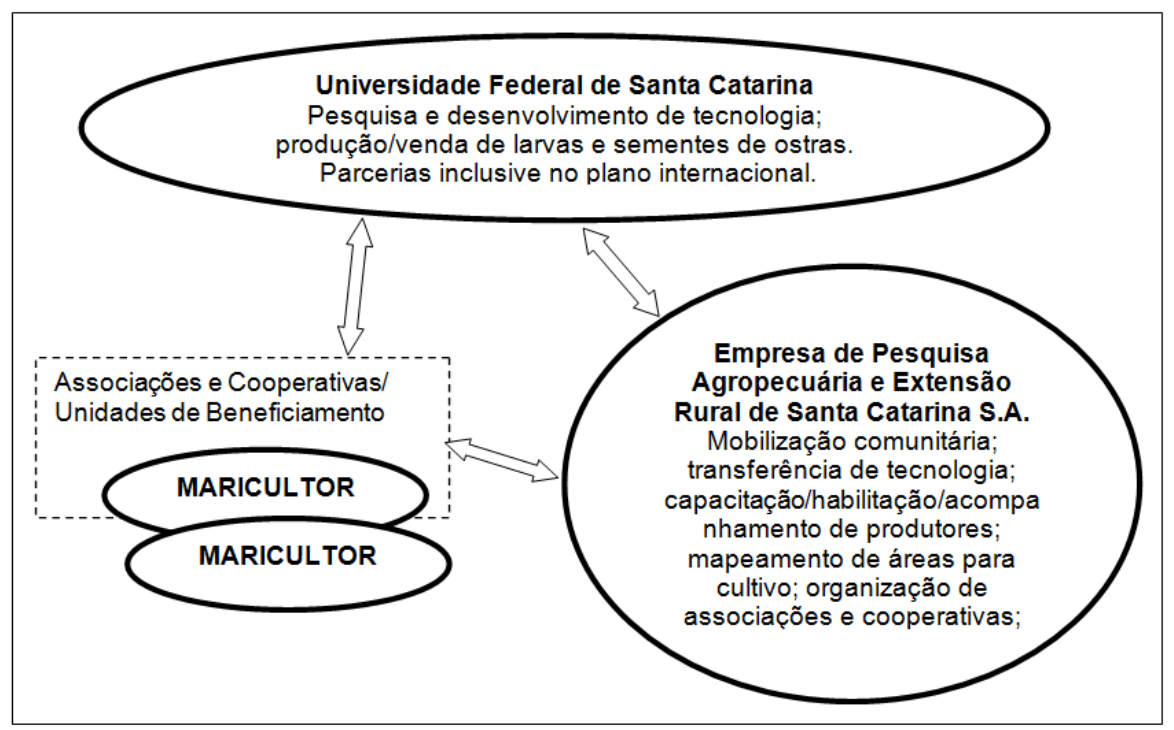

FONTE: elaboração do autor a partir de Gramkow (2002) e Vinatea (2000) 
Mostrou importância nesse movimento o chamado capital humano, ligado à tradição pesqueira das comunidades. Foi o conhecimento impregnado nas localidades que propiciou aquele entrelaçamento fértil e favoreceu a adaptação de tecnologias vindas de outros países e regiões brasileiras, traduzindo-se até na opção por materiais disponíveis nas próprias comunidades. É exemplo o uso de estacas de bambu no cultivo de mexilhões pelo sistema fixo em mesas, um recurso que, embora menos durável comparativamente, representa custos de instalação inferiores e favorece a participação de famílias pobres.

Também na ostreicultura pode-se encontrar ilustração, como nas caixas flutuantes para depósito das sementes de ostra na água, desenvolvidas pelos pesquisadores da UFSC junto com os produtores. Alguns ostreicultores tinham passado a utilizar essa forma de colocação por conta própria, em substituição a outras (como a "lanterna", por exemplo). O trabalho dos pesquisadores visando o aprimoramento resultou em sistema que proporciona resultados superiores aos de outras formas conhecidas. Na raiz, como se observa, está a interação entre pesquisadores e grupos de maricultores.

A citada parceria entre o então LCMM e a CIDA repercutiu no fortalecimento da infraestrutura laboratorial, envolvendo equipamentos, transferência tecnológica e disseminação de conhecimento técnico. Isso favoreceu desempenho manifestado, entre outras coisas, no imprescindível papel desse laboratório como produtor e distribuidor de sementes de ostras do Pacífico entre os produtores. Aspecto problemático dessa relação é a dependência dos ostreicultores, mas também quanto a isso avanços parecem ter sido logrados, pois passou-se a buscar desenvolvimento tecnológico que representasse garantia de autoabastecimento aos produtores. O "assentamento remoto", já utilizado em outros países, é técnica capaz de atender a essa necessidade. Mesmo exigindo a compra de larvas - principalmente nos Estados Unidos -, representa menores custos de produção, entre outras vantagens. Assim, continuam a ter destaque na estrutura do LMM os setores de assentamento de sementes e de larvicultura.

Para realçar a importância dessas interações entre universidade e tecido produtivo, cabe ressaltar que o avanço da maricultura provocou maior atenção para com o meio ambiente na costa de Santa Catarina. A razão é óbvia: a qualidade das águas é um requisito básico para o cultivo de espécies marinhas, mostrando-se sintomático o envolvimento, no implicado tecido institucional, de órgãos dos planos federal e estadual com atuação nessa esfera. Digno de nota é que o engajamento de numerosos contingentes nos cultivos parece ter fortalecido o sentido de preservação ambiental nas comunidades. Mais do que só atenção sobre a qualidade das águas, as localidades passaram a registrar monitoramento e controle sobre práticas como despejo de efluentes domésticos no mar.

Mas também aspectos socioeconômicos merecem realce. A expansão dos cultivos representou oportunidades de trabalho nessas comunidades (Machado 
2002; Rosa 1997; Vinatea 2000), sendo próximo de 750 o contingente de produtores atualmente registrados, organizados em 24 associações presentes em 12 municípios (www.epagri.rct-sc.br/). Os reflexos nos rendimentos estariam a justificar a opção de diversas famílias, como sugerido por alguns estudos de campo (Vinatea op cit.; Silveira 1999), dando coerência às mudanças de percepção sobre a maricultura em diferentes locais. Machado (op cit.: 164) constatou que a introdução dessa prática na localidade de Ribeirão da Ilha (Município de Florianópolis) suscitou "mudança da estrutura produtiva e melhoria da qualidade de vida local", mesmo que, no período estudado, essa atividade não acrescentasse mais do que um salário mínimo à renda das famílias envolvidas.

\section{Interações entre universidade e tecido produtivo: o vestuário}

Embora sem termo de comparação com outras regiões catarinenses onde as atividades têxteis e vestuaristas têm presença histórica, Florianópolis e sua área registram produção de artigos de vestuário. Trata-se de fabricação de artigos de moda diversificados, vendidos em mercados principalmente locais e regionais.

Muito do que se observa nesse setor em tal região espelha iniciativa da administração municipal de Florianópolis em meados dos anos 1980, quando, no intuito de impulsionar a geração de emprego e renda em local de poucas oportunidades, a Prefeitura criou projeto para promover fabricantes de roupas da área, todos de micro e pequeno porte. Seu número era considerável, pois dados da Relação Anual das Informações Sociais (RAIS) para o início dos anos 1990 indicam que o Aglomerado Urbano de Florianópolis abrigava 279 desses estabelecimentos, com 2.287 empregados. Note-se que esses números captam só o lado "formal" de uma atividade notoriamente marcada por grande "informalidade".

Estratégica, porque sintonizada com a necessidade de fortalecer as atividades de conceber e criar produtos do vestuário, foi a abertura de um Bacharelado em Moda - Habilitação em Design de Moda na UDESC, em meados dos anos 1990, mais precisamente em 1996. O funcionamento desse curso estará no centro desta abordagem posteriormente.

Essas providências foram seguidas por rápido crescimento do número de empresas nos primeiros anos. Estudo do Instituto de Planejamento Urbano de Florianópolis no final da década de 1980 indicou que novas empresas surgiram e muitos empregos foram criados (Perfil 1989). No Município de Florianópolis, o número de empregos captado pela RAIS aumentou $40 \%$ entre 1994 e 1996, passando de 802 para 1.127. 
Mas essa indústria não atravessou sem percalços as mudanças macroeconômicas do Brasil nos anos 1990. A liberalização do comércio externo e a valorização da moeda nacional multiplicaram as importações, sobretudo de produtos asiáticos mais baratos. Na região de Florianópolis, esse processo, agravado por outros fatores internos, provocou o fechamento de várias empresas. A tabela 1, sobre o período 1994-2006, sugere os problemas criados por tal conjuntura. Logo após o Plano Real (1994), essas atividades sofreram uma contração só estancada no final daquela década. Dos quatro municípios que compõem o seu aglomerado urbano, apenas Florianópolis exibiu crescimento nos empregos entre 1994 e 1996, talvez devido às ações anteriores de promoção dessa indústria. Mas logo depois, como se o fôlego se esgotasse, também esse município amargou declínio. A mudança na política cambial em 1999 trouxe recuperação a partir do início dos anos 2000, sem que, todavia, houvesse retorno aos anteriores níveis de participação dessa indústria no total da indústria de transformação: em 1994, os empregos e estabelecimentos daquela representavam $1 / 5$ e 1/4, respectivamente, dos empregos e estabelecimentos desta, e em 2006 essas proporções tinham caído para 10,6\% e 14,3\%.

A crise dos anos 1990 teve outras consequências importantes. Pesquisa realizada no seu auge sugeriu existir convicção, entre os agentes envolvidos na produção vestuarista, de que as empresas em atividade eram quase sobreviventes, beneficiárias de estratégias adequadas (Lins 2002). Ou seja, uma certa "depuração" tivera lugar, mesmo que a predominância de micro e pequenas empresas persistisse, em que pese a observada tendência de relativa "concentração": dados da RAIS informam que a presença das empresas com até 9 assalariados diminuiu e que a do estrato superior das microempresas (de 10 a 19 empregados) cresceu, espelhando uma forte contração do número de estabelecimentos com até 9 empregados.

Todavia é importante destacar, antes de tudo, que parecem ter sido limitados os avanços em criação, pedra angular da competitividade na indústria de vestuário. Estudos que captaram aspectos dessa problemática na segunda metade dos anos 1990 salientam as carências e limitações existentes, fruto da ausência de progressos significativos mesmo diante das pressões competitivas do período. Embora diversos agentes reconhecessem ser essencial desenvolver, em face da enxurrada de produtos importados baratos, o estilismo e a modelagem, para melhorar a presença no mercado, a situação era precária em nível de firma ou de instituições envolvidas.

No momento atual a situação não é muito diferente, a julgar pelo que se mostra ser a tônica na capacitação empresarial. Rosa (2005) constatou mediante pesquisa de campo que os fabricantes costumam incorporar novidades aos seus produtos, acompanhando as tendências da moda. Contudo, as atividades de criação acontecem de forma "extremamente centralizada" (p. 82), querendo isso dizer que são quase prerrogativa dos proprietários das empresas, mesmo que em alguns (poucos) casos as tarefas de pesquisa e desenvolvimento en- 
volvam também estilistas, pertencentes ou não aos quadros de funcionários. A grande maioria dos que realizam essas atividades (os proprietários) não possui formação específica e tem o seu conhecimento vinculado à prática cotidiana, tão somente.

TABELA 1. PARTICIPAÇÃO DA INDÚSTRIA TÊXTIL, DO VESTUÁRIO E ARTEFATOS DE TECIDOS NA INDÚSTRIA DE TRANSFORMAÇÃO DO AGLOMERADO URBANO DE FLORIANÓPOLIS: 1994-2006

\begin{tabular}{|c|c|c|c|c|c|c|c|}
\hline Atividades & $\mathrm{M}$ & nicipios & Biguaçu & Florianópolis & Palhoça & São José & $\begin{array}{l}\text { Aglomerado } \\
\text { Urbano de } \\
\text { Florianópolis }\end{array}$ \\
\hline \multirow{21}{*}{ Empregos } & & 1994 & 188 & 802 & 153 & 1.144 & 2.287 \\
\hline & Indistria & 1996 & 47 & 1.127 & 79 & 596 & 1.849 \\
\hline & têxtil, do & 1998 & 44 & 544 & 100 & 1.005 & 1.693 \\
\hline & vestuárioe & 2000 & 67 & 427 & 115 & 1.125 & 1.734 \\
\hline & artefatos de & 2002 & 79 & 356 & 142 & 1.075 & 1.652 \\
\hline & tecidos & 2004 & 171 & 395 & 167 & 1.161 & 1.894 \\
\hline & (A) & 2006 & 95 & 669 & 362 & 2.029 & 3.155 \\
\hline & \multirow{7}{*}{$\begin{array}{l}\text { Indústria de } \\
\text { transformação } \\
\text { (B) }\end{array}$} & 1994 & 1.374 & 3.967 & 1.453 & 4.949 & 11.743 \\
\hline & & 1996 & 1.200 & 4.648 & 1.381 & 4.672 & 11.901 \\
\hline & & 1998 & 1.314 & 3.955 & 1.392 & 6.245 & 12.906 \\
\hline & & 2000 & 1.433 & 3.893 & 1.640 & 6.175 & 13.141 \\
\hline & & 2002 & 1.799 & 4.115 & 2.311 & 6.173 & 14.398 \\
\hline & & 2004 & 2.253 & 5.100 & 2.685 & 7.055 & 17.093 \\
\hline & & 2006 & 3.694 & 8.606 & 5.136 & 12.243 & 29.679 \\
\hline & \multirow{7}{*}{$A / B * 100$} & 1994 & 13,7 & 20,2 & 10,5 & 23,1 & 19,5 \\
\hline & & 1996 & 3,9 & 24,2 & 5,7 & 12,8 & 15,5 \\
\hline & & 1998 & 3,3 & 13,7 & 7,2 & 16,1 & 13,1 \\
\hline & & 2000 & 4,7 & 11,0 & 7,0 & 18,2 & 13,2 \\
\hline & & 2002 & 4,4 & 8,6 & 6,1 & 17,4 & 11.5 \\
\hline & & 2004 & 7,6 & 7,7 & 6,2 & 16,5 & 11,1 \\
\hline & & 2006 & 2,6 & 7,8 & 7,0 & 16,6 & 10,6 \\
\hline \multirow{21}{*}{$\begin{array}{l}\text { Estabele- } \\
\text { cimentos }\end{array}$} & & 1994 & 9 & 160 & 21 & 89 & 279 \\
\hline & Industria & 1996 & 8 & 171 & 19 & 90 & 288 \\
\hline & têxtil, do & 1998 & 3 & 124 & 26 & 85 & 238 \\
\hline & vestuario e & 2000 & 6 & 100 & 27 & 82 & 215 \\
\hline & artefatos de & 2002 & 8 & 100 & 37 & 95 & 240 \\
\hline & tecidos & 2004 & 10 & 121 & 39 & 102 & 272 \\
\hline & & 2006 & 10 & 104 & 44 & 101 & 259 \\
\hline & \multirow{7}{*}{$\begin{array}{l}\text { Indústria de } \\
\text { transformação } \\
\text { (B) }\end{array}$} & 1994 & 67 & 488 & 147 & 456 & 1.158 \\
\hline & & 1996 & 78 & 559 & 148 & 462 & 1.247 \\
\hline & & 1998 & 68 & 556 & 190 & 526 & 1.340 \\
\hline & & 2000 & 77 & 571 & 210 & 553 & 1.411 \\
\hline & & 2002 & 101 & 613 & 271 & 599 & 1.584 \\
\hline & & 2004 & 116 & 654 & 298 & 630 & 1.698 \\
\hline & & 2006 & 127 & 630 & 361 & 695 & 1.813 \\
\hline & \multirow{7}{*}{$A / B * 100$} & 1994 & 13,4 & 32,8 & 14,3 & 19,5 & 24,1 \\
\hline & & 1996 & 10,2 & 30,6 & 12,8 & 19,5 & 23,1 \\
\hline & & 1998 & 4,4 & 22,3 & 13,7 & 16,1 & 17,8 \\
\hline & & 2000 & 7,8 & 17,5 & 12,9 & 14,8 & 15,2 \\
\hline & & 2002 & 7,9 & 16,3 & 13,6 & 15,9 & 15,1 \\
\hline & & 2004 & 8,6 & 18,5 & 13,1 & 16,2 & 16,0 \\
\hline & & 2006 & 7,9 & 16,5 & 12,2 & 14,5 & 14,3 \\
\hline
\end{tabular}

FONTE: elaborado pelo autor com base nos dados da RAIS, de vários anos 
Esse quadro, assinale-se, corresponde a ambiente onde existe um importante curso superior de moda, implantado para formar profissionais justamente em estilismo e modelagem, atividades que representam o cerne do processo de criação. O aludido curso de moda da UDESC opera há quase quinze anos, interagindo com outras instituições ligadas à produção de artigos do vestuário e com as próprias empresas. Destaque-se que o curso participa em diversos eventos de moda, como o Floripa Fashion, ocasião em que os alunos expõem coleções conceituais de sua concepção. Para a UDESC, ações desse tipo representam oportunidades para divulgar o seu papel na formação de profissionais de moda, na expectativa de favorecer a posterior absorção dos alunos pelo tecido produtivo.

Ora, se o quadro referente à criação é o esboçado acima, e, mais amplamente, se a aspiração de tornar Florianópolis um polo irradiador de moda, conforme manifestado por diferentes atores no auge da crise dos anos 1990, não resultou em situação que autorize comemorar resultados realmente expressivos, os vínculos entre as estruturas de formação de quadros técnicos e profissionais, de um lado, e as empresas, de outro, devem ser postos em questão. A trajetória da indústria de vestuário local mostra o envolvimento, com particularidades que refletem os vários perfis, de estruturas de formação profissional vinculadas a instituições como o Serviço Nacional de Aprendizagem Industrial (SENAI) e o Serviço Nacional do Comércio (SENAC), além de escolas privadas, todas primordialmente voltadas à esfera técnica (Lins 2000). Entretanto, haja vista o foco deste artigo - cujo campo analítico são as interações entre universidade e tecido produtivo -, é o curso de moda da UDESC que deve figurar no centro daquelas indagações.

O Bacharelado em Moda da UDESC oferece os conteúdos necessários à formação em moda e estilismo, capacitando os alunos para avaliar e incorporar as tendências do processo de criação, em sintonia com a evolução tecnológica e as diferentes mudanças na indústria. Mas não se observa uma absorção efetiva dos egressos do curso pelo tecido empresarial da região. Esse problema apresenta-se duradouro. Pesquisa realizada junto aos egressos das duas primeiras turmas formadas pelo curso, em 2000 e 2001, constatou que menos de $10 \%$ da amostra de ex-alunos entrevistados trabalhavam como estilistas e/ou modelistas em empresas da região que fabricam artigos de vestuário; cerca de 1/4 atuavam como freelancers em criação e produção de moda ou de figurinos para teatro; e 36\% eram docentes em cursos técnicos ou superiores de moda (Overrath 2002). Esse quadro geral não mudou desde então. Informações obtidas pelo autor, em fevereiro de 2010, junto à chefe do Departamento de Moda da UDESC indicam que, atualmente: a maioria dos egressos encaminha-se à docência em cursos técnicos ou superiores de moda, em Florianópolis ou em outras cidades catarinenses; é muito reduzida a percentagem dos que entram no setor produtivo, quer dizer, são contratados por empresas do setor vestuarista; essa proporção é ainda menor quando se considera a contratação por empresas da região de Florianópolis, pois os 
poucos alunos bem sucedidos nesse processo tendem a trabalhar no Vale do Itajaí, principal reduto das indústrias têxteis e vestuaristas de Santa Catarina e um dos mais importantes do Brasil.

A rigor, segundo constatou Rosa (2005) em empresas da região de Florianópolis, há mesmo desconhecimento, no tecido produtivo local, sobre as atividades do programa de formação da UDESC. E o ponto principal a ser destacado é que esse estranhamento não é fortuito. Nas empresas, "a principal necessidade de mão de obra (...) [refere-se àquela] voltada para o processo de montagem, ou seja, (...) pessoas que entendam melhor o processo de preparação e costura das peças" (Rosa \& Torrinelli 2005: 61). O realce de aspectos dessa natureza, relativamente à formação de recursos humanos em sintonia com os interesses dos fabricantes locais, transparece igualmente em outros estudos. Pesquisa realizada em 2009 junto a 14 empresas observou ser "unânime a constatação de que não há disponibilidade de mão de obra qualificada na região que possa atender às demandas das empresas, fazendo-se necessária uma maior oferta de cursos nas áreas de qualidade, corte/costura e atendimento ao cliente" (Souza 2009: 79).

Entretanto, na formação que oferece, o curso de moda da UDESC tem priorizado as etapas de criação e modelagem com ênfase em questões conceituais, sem uma necessária articulação, portanto, com as reais necessidades das empresas. Não admira, assim, que na pesquisa anteriormente mencionada se tenha constatado, nas empresas entrevistadas, "a quase total ausência de relações de cooperação (...) [com] empresas concorrentes, centros tecnológicos e universidades" (Souza op cit.: 89 - sublinhado na citação). É evidente que isso aponta para problemas nas relações entre universidade e tecido produtivo, do que decorre a observada dificuldade para o aluno egresso "ser aceito no mercado de trabalho da região de Florianópolis" (Rosa \& Torrinelli op cit.: 61).

O curso é, inegavelmente, um atributo estratégico do ambiente vestuarista local e regional. Um aspecto disso é a sua interação com várias instituições, uma das quais é o SEBRAE-SC, o que favoreceu o acesso a especialistas para ministrar palestras aos alunos, e uma outra é a FIESC, o que ajudou na atualização do curso sobre o perfil dos fabricantes. Cabe ainda mencionar vínculos com associações de fabricantes, possibilitando alguma projeção rumo à indústria por meio de palestras de professores e exposições dos trabalhos dos alunos das últimas séries. Como indicado, o curso participa de eventos de moda organizados pelo empresariado, como nas diversas versões do Beira Mar Fashion, estando o seu destaque sugerido pelo fato de não raramente caber-lhe a abertura dos desfiles, pautada na exploração do "conceito de moda" (Viana 2001).

Mas isso não altera a situação de precário entrelaçamento entre o curso e a indústria de vestuário local. De um lado, tal problema estaria representando limitações à inserção do curso na realidade socioeconômica local e regional, certamente com prejuízo para o próprio curso. De outro lado, sugere que o 
tecido produtivo deixa de se beneficiar das potencialidades locais no tocante à geração de quadros funcionais que representam possibilidades de upgrade produtivo, inclusive na perspectiva da inovação.

O percurso cumprido pelo curso, no tocante à relação entre formaturas e abandonos de alunos, parece espelhar esses problemas. A figura 3 apresenta $o$ número de alunos formados a cada ano desde a primeira turma, que ingressou em 1996, e o número de abandonos. A primeira formatura ocorreu no primeiro semestre de 2000, pois o curso é semestral, mas preferiu-se apresentar os dados de cada ano, pela soma dos semestres. O quadro que emerge exibe, grosso modo, um abandono para cada duas formaturas: entre 2000 e 2009 houve 269 formaturas e 140 abandonos. Claro que essa relação não é fixa. Por exemplo, enquanto em 2001 os abandonos superaram consideravelmente as formaturas, em 2004 receberam o diploma 39 alunos, contra apenas 5 evasões.

FIGURA 3. NÚMERO DE ALUNOS FORMADOS E DE ABANDONOS NO BACHARELADO EM MODA - HABILITAÇÃO EM DESIGN DE MODA DA UNIVERSIDADE DO ESTADO DE SANTA CATARINA (2000-2009)

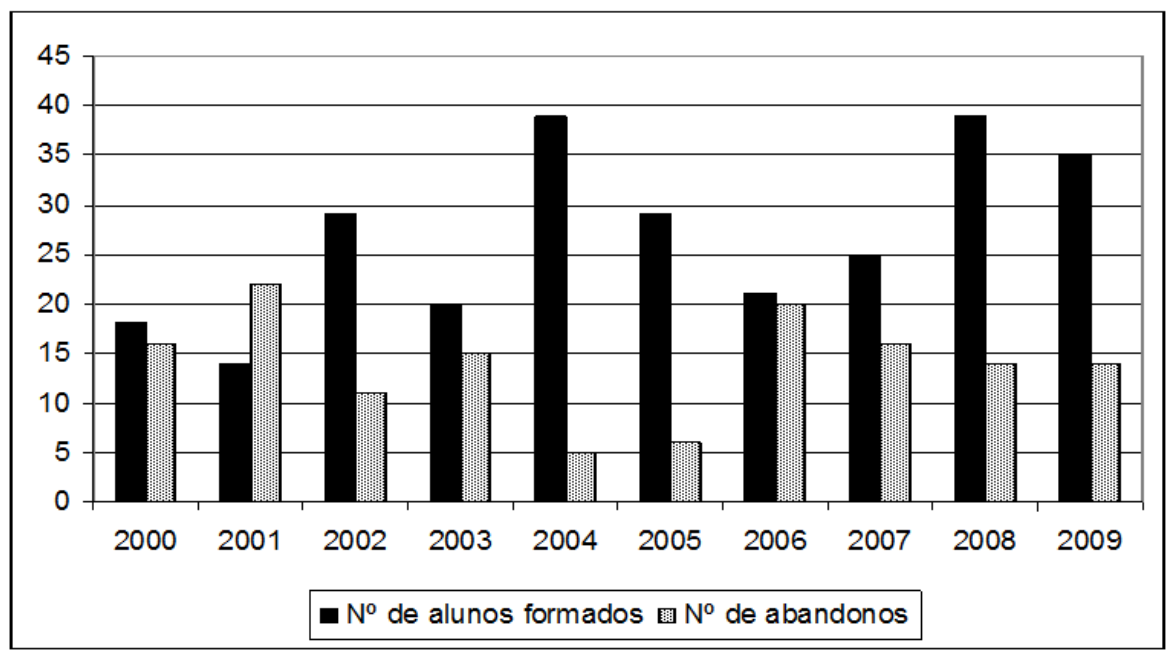

FONTE: elaborado pelo autor com base nos dados fornecidos pela secretaria do Bacharelado em Moda Habilitação em Design de Moda da UDESC

\section{Interações entre universidade e tecido produtivo: ma- ricultura versus vestuário}

Em texto idealizado para estimular o debate sobre as interações entre universidade e mundo empresarial no Brasil, Chaimovich (1999) indica ser uma 
responsabilidade da primeira, "inserida em (...) sociedade com profundas desigualdades sociais, incentivar relações com empresas que possibilitem geração de empregos e aumento de renda" (p. 22). É justo considerar que, pelo menos no plano das intenções, inscrevem-se nessa lógica os papeis desempenhados na região de Florianópolis pela UFSC e pela UDESC, relativamente à expansão da maricultura e ao fortalecimento da capacidade local para criação na indústria de vestuário, nessa ordem.

Mas, como observado, essas experiências de interação entre universidade e tecido produtivo apresentam-se bem distintas na maricultura e na indústria de vestuário, quer nos contornos e no escopo dos vínculos, quer nas suas repercussões e nos seus resultados.

Na maricultura esteve desde sempre presente o sentido de rede, com trocas sistemáticas de informações entre a esfera do conhecimento científico e a do conhecimento tradicional, esta segunda abarcando práticas das comunidades litorâneas impregnadas de história e cultura. Tal sentido de rede significou fertilização recíproca entre as atividades de pesquisa desenvolvidas na UFSC, em âmbito laboratorial, e as atividades de cultivo protagonizadas nas diferentes localidades onde lograram obter êxito os esforços da EPAGRI voltados à introdução e disseminação desse novo setor. O duradouro desempenho da UFSC na provisão de sementes de moluscos representa um importante "cimento" desse entrelaçamento.

Na indústria de vestuário, o sistema de ensino e pesquisa, focalizando prioritariamente o conceito de moda e exibindo uma forte presença da experimentação, não conseguiu o pretendido inter-relacionamento com a órbita da produção. Para as empresas, o ensino e a pesquisa disponibilizados no curso de moda da UDESC não contemplariam devidamente as suas necessidades, sendo possível falar em dissociação entre o que parece ser o interesse da universidade e o interesse da esfera produtiva. Assim, essas interações entre universidade e tecido produtivo mostrar-se-iam crivadas de uma aparente "intransigência" da primeira quanto à flexibilização do perfil conceitual e experimental da formação oferecida, de uma parte, e pela relutância da segunda frente aos "riscos" inerentes à contratação de profissionais não claramente harmonizados com as urgências empresariais, de outra parte.

Tudo indica que essa fraca interação entre o Bacharelado em Moda da UDESC e as empresas vestuaristas locais resulta, ao menos parcialmente, de problemas vinculados à comunicação entre agentes. Comunicação, aqui, não se refere a, simplesmente, dar a conhecer a sua existência: não há dúvida de que o tecido empresarial vestuarista da região sabe que o curso de moda da UDESC existe, a julgar pelos registros de participação de professores e alunos das últimas fases em variados tipos de atividades promovidas pelas iniciativas privada e pública (Rosa 2005). Por comunicação quer-se aludir, isto sim, à problemática da compatibilidade ou da sintonia entre as práticas dos agentes, assim como à adequada explicitação destas. Assinale-se que esta é uma importante 
questão do debate sobre interações entre universidade e tecido produtivo na perspectiva da Hélice Tripla, abordada na segunda seção deste artigo. A passagem abaixo ajuda a situar o problema.

O estudo da Hélice Tripla requer um modelo que complemente a perspectiva institucional com um foco em operações interativas em nível de sistema. As estruturas institucionais podem ser consideradas como as impressões digitais de estruturas de comunicação que foram funcionais até agora. Todos os atores e agências envolvidas são reflexivos, quer dizer, ajustam recorrentemente suas posições levando em conta barreiras institucionais e oportunidades. Competências comunicativas (...) tornam-se tão importantes quanto realizações em cada uma das hélices (Leydesdorff \& Etzkowitz 1996:283).

Nas interações entre o curso de moda da UDESC e a indústria de vestuário da região de Florianópolis, as competências comunicativas (conforme o sentido de comunicação aqui empregado) encontram-se, ao que parece, em questão. Não se trata, certamente, de problemas ligados à "tradução" de uma linguagem setorialmente específica ou à presença de "mensagens" culturalmente codificadas, como acontece entre agentes pertencentes a esferas ou setores marcadamente distintos. Afinal, o curso e o referido tecido empresarial possuem um só e mesmo objeto, praticamente: a produção de artigos de vestuário, com as diferentes questões envolvidas. Mas, do ponto de vista institucional, há diferença entre a linguagem da universidade e a linguagem dos negócios, quer dizer, há aparente dissociação, ao que tudo estaria a indicar, entre o interesse desse curso de moda e o que nesse se realiza e o interesse do tecido empresarial e o que nele se realiza. Esse hiato, que na perspectiva da Hélice Tripla se poderia chamar de comunicativo, figuraria na base do problemático quadro de interações entre universidade e tecido produtivo no caso em foco.

Há razões para imaginar que a situação é distinta na mais importante região têxtil e vestuarista de Santa Catarina, o Vale do Itajaí. São aspectos inegavelmente sugestivos a criação e o funcionamento, na estrutura do SENAI de Blumenau - principal cidade da região e centro de gravidade de um verdadeiro cluster têxtil e vestuarista -, de um Centro de Tecnologia do Vestuário (CTV) sintonizado com as exigências derivadas das mudanças pelas quais tem passado a cadeia produtiva têxtil em escala mundial (em que a moda e as funções implicando criação, como estilismo e modelagem, adquiriram um enorme peso). Essencial para o que interessa neste artigo é que, de um lado, o CTV "oferece cursos em nível de graduação (Bacharelado em Moda) e de pós-graduação (...), cursos superiores de tecnologia (...) e vários outros cursos técnicos, de aprendizagem industrial e de qualificação” (Lins 2008: 358), e, de outro lado, que entre "os usuários das diversas atividades desenvolvidas pelo CTV figuram empresas importantes (...) como Karsten, Hering e Marisol (...)" (idem).

Na maricultura, o nível de comunicação atingido entre os agentes implicados 
(comunicação entendida, repita-se, na perspectiva utilizada neste artigo) é sugerido pelos resultados da própria atividade de cultivar moluscos, anteriormente destacados. De fato, o desenvolvimento registrado é indissociável das interações entre a UFSC e a EPAGRI e entre estas e os produtores de moluscos. Aparece como subentendida uma aproximação das linguagens, sem o que a trajetória percorrida não teria sido possível. É nesse marco que cabe considerar aspectos como a permanente e regular disponibilização de sementes de ostras pelo LMM/UFSC e a adequada obtenção de sementes de mexilhões através de coletores, assim como o aperfeiçoamento dos maricultores relativamente ao manejo da produção.

Mas não há somente aspectos positivos nas interações em torno da maricultura. As tentativas de EPAGRI objetivando organizar os produtores em cooperativas nem sempre - talvez só minoritariamente - alcançaram o êxito pretendido pela instituição. Ligadas a unidades de beneficiamento, as cooperativas auxiliariam a equacionar problemas de comercialização dos moluscos, causados ou agravados por limitações de infraestrutura para beneficiamento e armazenagem que impõem a venda para intermediários, em detrimento de maiores ganhos para os produtores. O escasso interesse, ou mesmo a resistência, dos produtores representou frustração dessa iniciativa, a ponto de a própria EPAGRI estampar entre os chamados "pontos fracos" do cultivo comercial de moluscos em Santa Catarina "a fragilidade da estrutura organizacional da classe" (www.epagri.rect-sc.br). Pode-se considerar que se está diante de problemas de ordem comunicativa entre as esferas institucional e produtiva.

De todo modo, a experiência da maricultura estaria a reiterar a postulação, apresentada na segunda parte do artigo, de que as interações entre universidade e tecido produtivo costumam ser mais consequentes na escala local ou regional. A trajetória do cultivo de moluscos, inegavelmente escorada em entrelaçamento dessa natureza, representa alguma mudança em estruturas comunitárias litorâneas, abrindo perspectivas até então ausentes em matéria de geração de renda e ocupação. Já no setor de vestuário, as repercussões dos vínculos entre universidade e tecido produtivo ainda estão por ser testemunhadas. Carece ainda de demonstração, com efeito, a incrustada potencialidade para imprimir dinamismo em setor de atividade que, pela sua estrutura e por suas características, exibe clara "capilarização social”, ou seja, alguma disseminação ao nível das localidades.

\section{Considerações finais}

As trajetórias recentes da maricultura de moluscos e da produção de artigos de vestuário, dois setores de atividades da região de Florianópolis que foram objeto de inequívocas medidas de apoio institucional nas últimas décadas, 
podem ser consideradas no marco das relações entre universidade e tecido produtivo, como se destacou no estudo. Entretanto, essas duas experiências setoriais exibem casos bastante diferentes relativamente a tais vínculos: interações densas e duradouras, amplamente consequentes, na maricultura, e interações rarefeitas e erráticas, com escassos resultados aparentes, na indústria de vestuário.

A diferença parece implicar, em grande medida, problemas de "diálogo" entre as esferas envolvidas em ambos os percursos. Enquanto na maricultura, pelo que se observa, a comunicação entre UFSC, EPAGRI e produtores fluiu - e flui - adequadamente, mostrando-se multilateralmente profícua, no vestuário as diferenças de linguagens, querendo-se aqui falar de práticas e interesses, entre a universidade e o tecido empresarial revelaram-se um forte obstáculo.

Assim, para o vestuário, aproximar as esferas universitária e empresarial mediante projeções recíprocas, ainda que com a possível intermediação de agentes governamentais, seria procedimento estratégico. Estratégico não só para o fortalecimento desse setor de atividade e para uma melhor inserção social do Bacharelado em Moda da UDESC, mas, sobretudo, no sentido de contribuir para o desenvolvimento local e regional. Isso é importante em ambiente que necessita, tendo em vista o rápido crescimento populacional das últimas décadas, o aparecimento contínuo de novas oportunidades de trabalho e fontes de renda.

Na maricultura, não obstante os resultados obtidos, problemas de comunicação, no sentido privilegiado no artigo, entre as esferas institucional (EPAGRI) e produtiva precisam ser equacionados no que toca à criação de cooperativas de produtores, objetivando massificar a adesão dos maricultores distribuídos nas distintas localidades litorâneas participantes. Avançar ainda mais nesse setor, com adequada infraestrutura para beneficiamento e armazenagem e com capacidade de comercialização desvinculada da forte presença de intermediários, certamente significará um considerável impulso ao desenvolvimento local e regional.

\section{Referências}

BALDINI, Juliana P. \& BORGONHONI, Priscilla (2007). "A relação universidadeempresa no Brasil: surgimento e tipologias.” Caderno de Administração, 15(2):29-38.

BARARDI, Célia R. M. \& SANTOS, Chelen S. dos \& SIMÕES, Cláudia M. (2001). "Ostras de qualidade em Santa Catarina." Ciência Hoje, 29(172):70-73.

CHAIMOVICH, Hernan (1999). "Por uma relação mutuamente proveitosa entre universidade de pesquisa e empresas.” Revista de Administração, 34(4):18-22.

DAGNINO, Renato (2003). “A relação universidade-empresa no Brasil e o 'argumento da Hélice Tripla”. Revista Brasileira de Inovação, 2(2):268-307. 
DINIZ, Maria de F. S. \& OLIVEIRA, Ronise S. de (2006). "Interação universidadeempresa, empreendimento inovador e desenvolvimento local: um estudo de caso da incubadora CENTEV/UFV.” Locus Científico, 1(1):10-18.

ETZKOWITZ, Henry \& LEYDESDORFF, Loet (2000). “The dynamics of innovation: from National Systems and 'Mode 2' to a Triple Helix of university-industrygovernment relations." Research Policy, 29:109-123.

GODIN, Benoit \& GINGRAS, Yves (2000). “The place of universities in the system of knowledge production." Research Policy, 29:273-278.

GRAMKOW, Alessandra (2002). Redes e parcerias organizacionais: a experiência da maricultura catarinense. Florianópolis: Dissertação de Mestrado, Universidade Federal de Santa Catarina, Programa de Pós-Graduação em Administração.

HARLOE, Michael \& PERRY, Beth (2004). "Universities, localities and regional development: the emergence of the 'Mode 2' university?” International Journal of Urban and Regional Research, 28(1):212-223.

LEYDESDORFF, Loet \& ETZKOWITZ, Henry (1996). "Emergence of a Triple Helix of university-industry-government relations.” Science \& Public Policy, 23:279-285.

LEYDESDORFF, Loet \& ETZKOWITZ, Henry (1998). “The Triple Helix as a model for innovation studies.” Science \& Public Policy, 25(3):195-203.

LINS, Hoyêdo N. (2002). "Aprendizagem e inovação em uma área de produção confeccionista no Sul do Brasil.” In SBRAGIA, Roberto \& STAL, Eva (eds.). Tecnologia e inovação: experiências de gestão na micro e pequena empresa. São Paulo: PGT/USP, pp. 315-327.

LINS, Hoyêdo N. (2008). “Arranjo produtivo têxtil-vestuarista da região do Vale do Itajaí.” In CARIO, Silvio A. F. \& PANCERI, Reginete \& FLAUSINO, Elizabete S. \& BITTENCOURT, Márcio \& MONTIBELLER FILHO, Gilberto \& CAVALCANTI, Paulo R. (org.). Economia de Santa Catarina: inserção industrial e dinâmica competitiva. Blumenau: Nova Letra, pp. 336-381.

LUNDVALL, Bengt-Åke \& BORRÁS, Susana (1997). The globalising learning economy: implications for innovation policy. Brussels: European Commission, Directorate General XII - Science, Research \& Development.

MACHADO, Márcia (2002). Maricultura como base produtiva geradora de emprego e renda: estudo de caso para o Distrito de Ribeirão da Ilha, no Município de Florianópolis - SC - Brasil. Florianópolis: Tese de Doutorado, Universidade Federal de Santa Catarina, Programa de Pós-Graduação em Engenharia de Produção.

MIURA, Fernando (1996). “Ostra dá lucro no mar catarinense.” Folha de S. Paulo, 23 out.:8. (Caderno Agrofolha).

OVERRATH, Sabrina H. (2002). Perfil do egresso do Curso de Moda da Universidade do Estado de Santa Catarina. Florianópolis: Monografia de Conclusão de Curso, Universidade do Estado de Santa Catarina, Bacharelado em Moda Habilitação em Design de Moda.

PERFIL socioeconômico dos municípios de Florianópolis, São José, Palhoça e Biguaçu (1989). Florianópolis: Instituto de Planejamento Urbano de Florianópolis. 
ROSA, Lucas da (2005). A indústria do vestuário da Grande Florianópolis: absorção de estudantes do Curso Superior de Moda da UDESC. Florianópolis: Dissertação de Mestrado, Universidade do Estado de Santa Catarina, Programa de Pós-Graduação em Educação e Cultura.

ROSA, Rita de C. C. (1997). Impacto do cultivo de mexilhões nas comunidades pesqueiras de Santa Catarina. Florianópolis: Dissertação de Mestrado, Universidade Federal de Santa Catarina, Programa de Pós-Graduação em Aquicultura.

ROSA, Lucas da \& TORRINELLI, Marlene (2005). "Impacto do ensino voltado para a moda nas indústrias do vestuário da Grande Florianópolis.” ModaPalavra, 4:53-62.

SILVEIRA, Sérgio M. da (1999). O cultivo de mexilhões como alternativa para os pescadores artesanais: estudo exploratório sobre o Município de Governador Celso Ramos. Florianópolis: Monografia de Graduação, Universidade Federal de Santa Catarina, Graduação em Ciências Econômicas.

SOUZA, Aline M. B. de (2009). Avaliação das condições competitivas da indústria de confecção: um estudo nas micro e pequenas empresas da Região da Grande Florianópolis. Florianópolis: Monografia de Graduação, Universidade Federal de Santa Catarina, Graduação em Ciências Econômicas.

STORPER, Michael (1997). The regional world: territorial development in a global economy. New York: The Guilford Press.

SUTZ, Judith (2000). "The university-industry-government relations in Latin America." Research Policy, 29:279-290.

SUZIGAN, Wilson \& ALBUQUERQUE, Eduardo da M. e (2007). “A interação entre universidades e empresas em perspectiva histórica: uma investigação preliminar do caso brasileiro.” Seminário sobre Relações Universidade-Empresa no Sul do Brasil: Experiências e Possibilidades de Desenvolvimento Tecnológico para um Sistema Regional de Inovação. Florianópolis: UFSC-FINEP-FAPESC-FAPEU. Anais em CD.

VEDOVELLO, Conceição (2001). "Perspectivas e limites da interação entre universidades e MPMEs de base tecnológica localizadas em incubadoras de empresas." Revista do BNDES, 8(16):281-316.

VEDOVELLO, Conceição \& PUGA, Fernando P. \& FELIX, Mariana (2001). “Criação de infra-estruturas tecnológicas: a experiência brasileira de incubadoras de empresas." Revista do BNDES, 8(16):183-214.

VIANA, Natália (2001). "Moda ganha status profissional em SC.” Gazeta Mercantil Santa Catarina, 4 maio:5. (Caderno Estações).

VINATEA, Luis A. A. (2002). Modos de apropriação e gestão patrimonial de recusros costeiros: estudo de caso sobre o potencial e os riscos do cultivo de moluscos marinhos na Baía de Florianópolis. Florianópolis: Tese de Doutorado, Universidade Federal de Santa Catarina, Programa de Pós-Graduação Interdisciplinar em Ciências Humanas.

Recebido em: 28 de setembro de 2009

Primeira resposta em: 23 de novembro de 2009

Aceite em: 18 de março de 2010 
